\title{
Dual source computed tomography: automated, visual or dual analysis?
}

\author{
E. E. van der Wall · J. H. C. Reiber
}

Published online: 27 November 2008

(C) The Author(s) 2008. This article is published with open access at Springerlink.com

Over the past years, automated quantitative analysis of the coronary artery system has been developed and successfully clinically applied in particular for X-ray coronary angiography [1]. Recently, computer-aided analysis of the coronary arteries has been developed for ultrasound [2, 3], magnetic resonance imaging (MRI) [4], and lately also for computed tomography (CT) techniques [5, 6]. At present the major bottleneck of multi-slice computed tomography (MSCT) imaging of the coronary arteries is the potential lack of image quality due to limitations in the spatial and temporal resolution, irregular or high heart beat, respiratory effects, and variations of the distribution of the contrast agent. The number of rejected vessel segments in diagnostic studies is currently still too high for implementation in routine clinical practice. Until now, stenoses of the coronary arteries are evaluated visually with CT angiography [7-33]. Therefore, the results are highly dependent on subjective factors inherent in the examiner. New software tools for semi-quantitative analysis (CT-

E. E. van der Wall ( ()

Department of Cardiology, Leiden University Medical Center, P.O. Box 9600, Leiden, The Netherlands

e-mail: e.e.van_der_wall@lumc.nl

J. H. C. Reiber

Department of Radiology, Leiden University Medical

Center, P.O. Box 9600, Leiden, The Netherlands
QCA, quantitative coronary assessment) might be adequate to improve the diagnostic accuracy und reproducibility [6, 34]. However, also for the automated quantitative analysis of the coronary arteries high image quality is required. Based upon the trend in technological development of MSCT scanners, there is no doubt that the quantitative analysis of MSCT coronary angiography will benefit from these technological advances. Fischbach et al. [35] compared quantitative and qualitative information on global and LV function obtained with MSCT with that obtained with resonance imaging (MRI) in patients with a high prevalence of LV wall motion abnormalities in 30 patients with a variety of cardiac disease. Global LV function parameters from MDCT studies were measured using a commercially available software package for cardiac function analysis (CT MASS 6.1, Medis, Leiden, The Netherlands) supporting automatic endo- and epicardial contour detection. Global LV function parameters and wall thickness measurement from MRI studies were determined using the MRI-compatible version of the analysis software (MR MASS suite 6.1, Medis) on an offline workstation employing identical criteria to those used with the CT evaluation. Normokinetic segments were reliably identified with MSCT but the sensitivity for detection and accurate classification of LV wall motion abnormalities need to be improved. Better temporal resolution of the CT system seems to be the most important factor for enhancing MSCT performance. 
One of the recent technological advances in CT imaging is dual source computed tomography (DSCT), being on the market since 2006. DSCT improves imaging quality because of less heart rate dependency and offers a spatial resolution of $0.4 \mathrm{~mm}$ and a temporal resolution of $83 \mathrm{~ms}$ [34]. Busch et al. [36] compared 64-slice MSCT and DSCT with cardiac catheterization and showed a good correlation of grading stenoses between the software-assisted evaluation and the results of the coronary catheter angiography. The promising results of the DSCT are due to a superior temporal resolution compared to the 64 slice MSCT. Van der Vleuten et al. [37] compared left ventricular (LV) function by DSCT using MRI as reference standard in 34 patients. Global LV functional parameters calculated from DSCT datasets acquired in daily clinical practice correlated well with MRI and may be considered interchangeable. However, the authors found that visual assessment of the image quality of the short-axis cine slices should be performed to detect any artifacts in the DSCT data which could influence accuracy. Piers et al. [38] evaluated non-invasive angiography using DSCT for the determination of the most appropriate therapeutic strategy in 60 patients with suspected coronary artery disease (CAD). Although imaging quality did improve considerably, DSCT cannot be used for definitive therapeutic decision-making with regard to revascularization procedures in patients with suspected CAD.

Burgstahler et al. [39] showed that improved spatial and temporal resolution of DSCT was associated with better opacification of the coronary arteries and a better contrast with the myocardium independent of heart rate. Compared to MSCT, opacification of the coronary arteries at DSCT was not affected by body mass index (BMI). The main advantage of DSCT lies with the heart rate independency, which might have a positive impact on the diagnostic accuracy. Groen et al. [40] compared MRI, 64-slice MSCT and DSCT in assessing global LV function parameters using a moving heart phantom. A good correlation was found between DSCT and MRI for LV ejection fraction and cardiac output. MRI systematically underestimated functional cardiac parameters, LV ejection fraction and cardiac output of a moving heart phantom. 64-slice MSCT underestimated or overestimated these functional parameters depending on the heart rate because of limited spatial resolution. DSCT showed minimal deviations from these functional parameters compared to MRI, electron beam tomography and 64slice MSCT.

Alkahdi et al. [41] determined the radiation doses and image quality of different DSCT protocols tailored to heart rate and BMI in 200 patients. It was concluded that DSCT was associated with radiation doses ranging between 1.3 and $9.0 \mathrm{mSv}$, depending on the protocol used. When the DSCT protocol will be tailored to heart rate and BMI of the individual patient, this will result in dose reductions of up to $86 \%$ while maintaining a diagnostic image quality of the examination. This finding was underscored by Weustink et al. [42], who showed that optimal ECG pulsing, radiation exposure to patients, particularly those with low or high heart rate, can be reduced with preservation of image quality. Juergens et al. [43] evaluated software for threshold-based 3D segmentation of the left ventricle in comparison with traditional 2D short axis-based planimetry (Simpson method) for measurement of LV volume and global LV function with state-of-the-art DSCT in 50 patients. Inter-observer variation with $3 \mathrm{D}$ segmentation analysis was significantly less than with the $2 \mathrm{D}$ technique, and mean analysis time was significantly shorter for 3D analysis. It was concluded that automated threshold-based 3D segmentation enables accurate and reproducible DSCT assessment of LV volume and function with excellent correlation with results of 2D short-axis analysis. Exclusion of papillary muscles from LV volume resulted in small systematic differences in quantitative values. Confirmation of these data by trials in larger patient collectives is warranted.

In the current issue of the International Journal of Cardiovascular Imaging, Reimann et al. [44] analyzed the diagnostic efficacy of computer-aided analysis of relevant coronary artery stenosis using DSCT. Based on a 13-segment model 30 CT scans were analyzed for significant stenoses using conventional 3D-charts as well as a specialized cardiac analysis tool (CAT). Diagnostic accuracy and time to diagnosis was recorded for each vessel separately as well as the three readers' confidence. With severe coronary artery calcifications, 53 false interpretations of segments were found for the total of 390 coronary segments analyzed. Similar negative and positive predictive values were shown for $3 \mathrm{D}$-charts and CAT 
analysis. Analysis of $3 \mathrm{D}$ charts took a mean of $5.2 \mathrm{~min}(3-10 \mathrm{~min})$ versus a mean time of $8.2 \mathrm{~min}$ (4-12 min) for CAT analysis. No significant interreader time differences and no significant confidence level differences were found between readers and analyses. It was concluded that a specialized CAT of the coronary tree shows comparable accuracy to manual 3D analysis but needs improvements concerning coronary tree segmentation times.

In summary, the study of Reimann et al. [44] clearly shows that automated and computer-aided quantitative approaches are very promising in CT imagingcertainly in combination with high technology CT scanners-but they are still time-consuming and currently not suitable to establish a first line diagnosis in patients with suspected CAD. In the near future, computer analysis times will considerably shorten to such an extent that automated approaches provide excellent alternatives to, or even preferred over, purely visual approaches. At the moment dual source systems require at least 'dual' analysis.

Open Access This article is distributed under the terms of the Creative Commons Attribution Noncommercial License which permits any noncommercial use, distribution, and reproduction in any medium, provided the original author(s) and source are credited.

\section{References}

1. Tuinenburg JC, Koning G, Hekking E et al (2000) American college of cardiology/European society of cardiology international study of angiographic data compression phase II: the effects of varying JPEG data compression levels on the quantitative assessment of the degree of stenosis in digital coronary angiography. Joint photographic experts group. J Am Coll Cardiol 35:1380-1387

2. Mitchell SC, Bosch JG, Lelieveldt BP, van der Geest RJ, Reiber JH, Sonka M (2002) 3-D active appearance models: segmentation of cardiac MR and ultrasound images. IEEE Trans Med Imaging 18:317-324

3. Koning G, Dijkstra J, von Birgelen C et al (2002) Advanced contour detection for three-dimensional intracoronary ultrasound: a validation-in vitro and in vivo. Int J Cardiovasc Imaging 18:235-248

4. van der Geest RJ, de Roos A, van der Wall EE, Reiber JH (1997) Quantitative analysis of cardiovascular MR images. Int J Card Imaging 13:247-258

5. Schuijf JD, Pundziute G, Jukema JW et al (2007) Evaluation of patients with previous coronary stent implantation with 64-section CT. Radiology 245:416-423

6. Marquering HA, Dijkstra J, de Koning PJ, Stoel BC, Reiber JH (2005) Towards quantitative analysis of coronary CTA. Int J Cardiovasc Imaging 21:73-84
7. de Leeuw JG, Wardeh A, Sramek A, van der Wall EE (2007) Pseudo-aortic dissection after primary PCI. Neth Heart J 15:265-266

8. van Lennep JE, Westerveld HT, van Lennep HW, Zwinderman AH, Erkelens DW, van der Wall EE (2000) Apolipoprotein concentrations during treatment and recurrent coronary artery disease events. Arterioscler Thromb Vasc Biol 20:2408-2413

9. van der Wall EE, Heidendal GA, den Hollander W, Westera G, Roos JP (1980) I-123 labeled hexadecenoic acid in comparison with thallium-201 for myocardial imaging in coronary heart disease. A preliminary study. Eur J Nucl Med 5:401-405

10. Bavelaar-Croon CD, Kayser HW, van der Wall EE et al (2000) Left ventricular function: correlation of quantitative gated SPECT and MR imaging over a wide range of values. Radiology 217:572-575

11. Bavelaar-Croon CD, Pauwels EK, van der Wall EE (2001) Gated single-photon emission computed tomographic myocardial imaging: a new tool in clinical cardiology. Am Heart J 141:383-390

12. Bax JJ, Lamb H, Dibbets P et al (2000) Comparison of gated single-photon emission computed tomography with magnetic resonance imaging for evaluation of left ventricular function in ischemic cardiomyopathy. Am J Cardiol 86:1299-1305

13. van Rugge FP, Holman ER, van der Wall EE, de Roos A, van der Laarse A, Bruschke AV (1993) Quantitation of global and regional left ventricular function by cine magnetic resonance imaging during dobutamine stress in normal human subjects. Eur Heart J 14:456-463

14. Tulevski II, Hirsch A, Sanson BJ et al (2001) Increased brain natriuretic peptide as a marker for right ventricular dysfunction in acute pulmonary embolism. Thromb Haemost 86:1193-1196

15. Braun S, van der Wall EE, Emanuelsson S, Kobrin I (1996) Effects of a new calcium antagonist, mibefradil (Ro 405967), on silent ischemia in patients with stable chronic angina pectoris: a multicenter placebo-controlled study. The mibefradil international study group. J Am Coll Cardiol 27:317-322

16. Molhoek SG, Bax JJ, Bleeker GB et al (2004) Comparison of response to cardiac resynchronization therapy in patients with sinus rhythm versus chronic atrial fibrillation. Am J Cardiol 94:1506-1509

17. van der Wall EE, van Dijkman PR, de Roos A et al (1990) Diagnostic significance of gadolinium-DTPA (diethylenetriamine penta-acetic acid) enhanced magnetic resonance imaging in thrombolytic treatment for acute myocardial infarction: its potential in assessing reperfusion. Br Heart $\mathbf{J}$ 63:12-17

18. van Dijkman PR, van der Wall EE, de Roos A et al (1991) Acute, subacute, and chronic myocardial infarction: quantitative analysis of gadolinium-enhanced MR images. Radiology 180:147-151

19. Langerak SE, Vliegen HW, de Roos A et al (2002) Detection of vein graft disease using high-resolution magnetic resonance angiography. Circulation 105:328-333

20. Leber AW, Knez A, Becker A et al (2005) Visualising noncalcified coronary plaques by $\mathrm{CT}$. Int $\mathrm{J}$ Cardiovasc Imaging 21:55-61 
21. Pundziute G, Schuijf JD, Jukema JW et al (2007) Noninvasive assessment of plaque characteristics with multislice computed tomography coronary angiography in symptomatic diabetic patients. Diabetes Care 30:11131119

22. Schuijf JD, Jukema JW, van der Wall EE, Bax JJ (2007) Multi-slice computed tomography in the evaluation of patients with acute chest pain. Acute Card Care 9:214-221

23. van Werkhoven JM, Schuijf JD, Jukema JW et al (2008) Anatomic correlates of a normal perfusion scan using 64slice computed tomographic coronary angiography. Am J Cardiol 101:40-45

24. Pundziute G, Schuijf JD, Jukema JW et al (2007) Prognostic value of multislice computed tomography coronary angiography in patients with known or suspected coronary artery disease. J Am Coll Cardiol 49:62-70

25. Schuijf JD, Pundziute G, Jukema JW et al (2006) Diagnostic accuracy of 64-slice multislice computed tomography in the noninvasive evaluation of significant coronary artery disease. Am J Cardiol 98:145-148

26. Schuijf JD, Wijns W, Jukema JW et al (2006) Relationship between noninvasive coronary angiography with multislice computed tomography and myocardial perfusion imaging. J Am Coll Cardiol 48:2508-2514

27. Jongbloed MR, Lamb HJ, Bax JJ et al (2005) Noninvasive visualization of the cardiac venous system using multislice computed tomography. J Am Coll Cardiol 45:749-753

28. Juwana YB, Wirianta J, Suryapranata H, de Boer MJ (2007) Left main coronary artery stenosis undetected by 64-slice computed tomography: a word of caution. Neth Heart J 15:255-256

29. Schuijf JD, Bax JJ, van der Wall EE (2007) Anatomical and functional imaging techniques: basically similar or fundamentally different? Neth Heart J 15:43-44

30. Wijpkema JS, Dorgelo J, Willems TP et al (2007) Discordance between anatomical and functional coronary stenosis severity. Neth Heart J 15:5-11

31. van de Wal RM, van Werkum JW, le Cocq d'Armandville MC et al (2007) Giant aneurysm of an aortocoronary venous bypass graft compressing the right ventricle. Neth Heart J 15:252-254

32. Henneman MM, Schuijf JD, Pundziute G et al (2008) Noninvasive evaluation with multislice computed tomography in suspected acute coronary syndrome: plaque morphology on multislice computed tomography versus coronary calcium score. J Am Coll Cardiol 52:216-222

33. Schuijf JD, Beck T, Burgstahler C et al (2007) Differences in plaque composition and distribution in stable coronary artery disease versus acute coronary syndromes; non- invasive evaluation with multi-slice computed tomography. Acute Card Care 9:48-53

34. Roberts WT, Bax JJ, Davies LC (2008) Cardiac CT and CT coronary angiography: technology and application. Heart 94:781-792

35. Fischbach R, Juergens KU, Ozgun M et al (2007) Assessment of regional left ventricular function with multidetector-row computed tomography versus magnetic resonance imaging. Eur Radiol 17:1009-1017

36. Busch S, Nikolaou K, Johnson T et al (2007) Quantification of coronary artery stenoses: comparison of 64-slice and dual source CT angiography with cardiac catheterization. Der Radiologe 47:295-300

37. van der Vleuten PA, de Jonge GJ, Lubbers DD et al (2008) Evaluation of global left ventricular function assessment by dual-source computed tomography compared with MRI. Eur Radiol. doi:10.1007/s00330-008-1138-z

38. Piers LH, Dikkers R, Willems TP et al (2008) Computed tomographic angiography or conventional coronary angiography in therapeutic decision-making. Eur Heart J. doi:10.1093/eurheartj/ehn454

39. Burgstahler C, Reimann A, Brodoefel H et al (2008) Quantitative parameters to compare image quality of noninvasive coronary angiography with 16-slice, 64-slice and dual-source computed tomography. Eur Radiol. doi:10.1007/s00330-008-1201-9

40. Groen JM, van der Vleuten PA, Greuter MJ, Zijlstra F, Oudkerk M Comparison of MRI, 64-slice MDCT and DSCT in assessing functional cardiac parameters of a moving heart phantom. Eur Radiol. doi:10.1007/s00330008-1197-1

41. Alkadhi H, Stolzmann P, Scheffel H et al (2008) Radiation dose of cardiac dual-source CT: the effect of tailoring the protocol to patient-specific parameters. Eur $\mathrm{J}$ Radiol. doi:10.1016/j.ejrad.2008.08.015

42. Weustink AC, Mollet NR, Pugliese F et al (2008) Optimal electrocardiographic pulsing windows and heart rate: effect on image quality and radiation exposure at dual-source coronary CT angiography. Radiology 248:792-798

43. Juergens KU, Seifarth H, Range F et al (2008) Automated threshold-based 3D segmentation versus short-axis planimetry for assessment of global left ventricular function with dual-source MDCT. AJR Am J Roentgenol 190: 308-314

44. Reimann AJ, Tsiflikas I, Brodoefel H et al (2009) Efficacy of computer aided analysis in detection of significant coronary artery stenosis in cardiac using dual source computed tomography. Int $\mathrm{J}$ Cardiovasc Imaging. doi:10.1007/s10554-008-9372-7 